\title{
Factor-Biased Technical Change and Specialization Patterns
}

\author{
Jürgen Meckl; Ivan Savin ${ }^{\dagger \ddagger}$ \\ Submitted: 17.12.2018, Accepted: 10.03.2018
}

\begin{abstract}
We analyze the medium- and long-run effects caused by an inflow of capital into a labor-abundant country. For that purpose, we incorporate directed technical change into a Heckscher-Ohlin model with a continuum of goods. This provides a comprehensive theory explaining the dynamics of comparative advantage based on differences in effective factor endowments, i.e. factor endowments adjusted by differences in technological levels. Our model constitutes an appropriate framework for understanding, e.g., the empirically observed changes in industrial structures of Central and Eastern European countries. Furthermore, we provide a theoretical foundation for the empirical Prospective Comparative Advantage index with new insights into the future dynamics of comparative advantage. Eventually, we show the importance of research spillovers and state dependence on the process of convergence.
\end{abstract}

Keywords: comparative advantage, technological progress, dynamic processes, innovation, factor-biased technical change

JEL Classification: F21, F43, O33

\footnotetext{
*Justus Liebig University of Giessen; e-mail: Juergen.Meckl@wirtschaft.uni-giessen.de

${ }^{\dagger}$ Karlsruhe Institute of Technology, Germany

$\ddagger$ Université de Strasbourg - CNRS, France

$\S$ Ural Federal University, Russian Federation
} 


\section{Introduction}

David Ricardo's theory of comparative advantage is one of the most important explanations of the pattern of trade. Neoclassical trade theories typically elaborate on comparative advantage within static models thus considering comparative advantage as an atemporal phenomenon. Comparative advantage, however, is by no means a static phenomenon. This is highlighted by several empirical observations. For instance, South Korea is an impressive example of a country that went in 50 years from war-torn devastation to leading players in several important high-tech markets for consumer-electronic products or automobiles (see Lee and Lim 2001 for more discussion). Taiwan is another example that experienced a rapid change in its trade pattern, and China is expected to take that step, too. Additionally, for several new member states of the European Union, Zaghini (2005) reports comparable changes in trade patterns. Whereas these transition countries were exporting primarily goods making intensive use of natural and labor resources (agricultural goods, steal products and glass) in the beginning of the 1990s, they experienced considerable growth in comparative advantage in some capital-intensive industries such as transport, machinery building and electronics since then. Although such drastic changes in comparative advantage are rare, they are nevertheless remarkable. Such anecdotal evidence (or stylized facts) makes one wonder about the dynamics of comparative advantage that may have led to such an outcome of acquisition of comparative advantage in erstwhile imported commodities.

Neoclassical trade theory attributes comparative advantage either to differences in relative factor endowments (factor-abundance models like the Heckscher-Ohlin model) or to international technology differences (Ricardian trade models). Both sorts of differences are assumed to be exogenously given by these theories. More recent contributions from growth theory emphasize a direct link between both mechanisms. Acemoglu's argument of directed technical change (Acemoglu 1998, 2002) states that the degree of division of labor and of other production factors is endogenous - it results from firms' investments into alternative forms of technological improvements - and depends on relative factor endowments. As a result, this theory of directed technical change serves as a platform of an endogenous explanation of technological differences on the basis of factor endowments and thus provides an ideal framework for analyzing the dynamics of comparative advantage.

This paper explores the following research question: by what kind of a dynamic comparative advantage process does a country in the South - in the tradition of the North-South models in development economics, we take up this classification and interpret North countries as industrialized countries and South countries as newly industrialized or developing countries - acquire comparative advantage, due to capital movements from North to South? We argue that induced technical change is the relevant mechanism for thinking about dynamic comparative advantage in such cases. To this end, this paper develops a two-country general equilibrium model with a continuum of goods with a similar structure to the model in Dornbusch et al. (1980) 
Factor-Biased Technical Change and Specialization Patterns

- DFS hereafter -, with the novelty that technical change is endogenously determined and may be biased towards different factors of production. For related work, see, e.g., product-cycle models such as Krugman (1979) or Antràs (2005) or imitation models such as Helpman (1993). Similarly to Acemoglu (2002), in our model capital and labor are transformed into machines that can be used to produce capital or labor intermediate inputs. Each machine producer is a monopolist and chooses between producing a machine to make the capital intermediate input or a machine to make the labor intermediate input. Capital, labor, machines, and intermediate inputs are immobile across countries. The capital and labor intermediate inputs are combined to produce one variety of the final good, which is internationally traded. We characterize the equilibrium properties of the model, and use the model to study the equilibrium effects of a capital reallocation from the capital abundant country to the capital scarce country.

At a technical level, our contribution builds into the DFS model an endogenous mechanism of innovation via capital-augmenting or labor-augmenting machines. The larger the set of machines that can be used to produce the capital intermediate input in a country, the higher the effective productivity of the country's capital stock. The same holds for the set of machines that produce the labor intermediate input that enhances the productivity of its workers. This assumption typical to the theories of growth since Romer (1990) has been also empirically supported by Frensch and Gaucaite Wittich (2009). This happens because, given the assumed technology to transform machines into intermediate inputs, the larger the set of machines to produce the capital (labor) intermediate input, the smaller the amount of capital (labor) allocated to the production of each type of machine, and thus the larger the marginal productivity of capital (labor). In this regard, we take on board the conclusion of Treffer $(1993,1995)$, who emphasizes that cross-country differences in factor supplies, in conjunction with technology differences, are consistent with empirical findings on the factor content of international trade. To accommodate this assumption in our model, we consider factor endowments in effective units as the basis for factorabundance driven trade.

We find that if innovation depends on the mix of intermediates produced, the following holds. As capital moves to the South and the country produces more of the capital intermediate, it will become relatively better at producing capital machines, and interestingly enough, this occurs in a general case (although we do identify a special case in which this conclusion is vitiated; and as we explain later, this unusual case arises when the intensities of knowledge spillovers are the same in both countries). As a result, the South gains comparative advantage in capital-intensive goods and expands the range of goods produced at its upper end of capital intensities. In our model with induced technical change, there is a market size effect similar to Grossman and Helpman (1993, Chapter 8). But in contrast to Grossman and Helpman (1993, Chapter 8) who consider a case in which innovation in a sector depends on output in the sector by generic learning by doing, we relate sectors to factors (the $K$ sector, 
the $L$ sector) and thus essentially unpack where the innovation is coming from. This is another perspective from which our work can be seen.

Not only do we argue that induced technical change is a relevant mechanism that drives dynamic comparative advantage, but cases such as South Korea provide justification for our claim that R\&D is being done heavily in a developing country also, which in our model is a central driver of dynamic comparative advantage acquisition (see Puga and Trefler (2010), who find empirical evidence in support of this hypothesis). Since we deal with the case in which the property of local factorprice equalization is violated, it follows the capital recipient is a developing country (Neary 1985). While it is not typical to think of innovation as occurring in such a country, there is mounting evidence that in the 21st century this is indeed the case in several countries. Also, in our model, as in most trade models, all final goods are internationally traded, but all inputs are internationally non-traded. As Sen (2008) articulates elegantly, as only he can, that in 'The Discipline of Economics', the choice of assumptions in economic models is driven by the purpose for which the specific model is designed. Since our purpose in this paper is to examine plurality of endogenous dynamic comparative advantage acquisition processes, our primary concern is not with endogenous international factor mobility. For example, if an aeronautical engineer, solely interested in designing an aerodynamically efficient shape of an aircraft were asked, 'since seats and people would actually be in the aircraft, why tiny plastic seats and small wooden people were missing from the inside of the model craft that is being put through a wind tunnel?', she would shrug her shoulders and declare such details to be, 'not material, your honor!'

There are also other studies that account for technology differences between countries in Heckscher-Ohlin framework as the DFS-type model. Zhu and Treffer (2005) explain inequalities in factor prices by exogenous technological convergence between countries, while Zhu (2007) examines welfare implications of this type of convergence. In contrast, to our knowledge the present paper is the first analyzing the causes triggering this technology convergence by endogenizing decisions to invest in new technologies.

The paper is organized as follows. Section 2 presents the basic model. In Sections 3 and 4 we analyze the static and the dynamic equilibrium of the model. Section 5 introduces international capital-market integration and analyzes dynamics of comparative advantage conditional upon changes in factor endowments. Section 6 contains some concluding remarks, including those pertaining to implications for policy and for predicting the evolution of comparative advantage. 
Factor-Biased Technical Change and Specialization Patterns

\section{The Model}

\subsection{Consumer Problem}

Consumers in all countries are assumed to have identical preferences of the constant relative risk aversion (CRRA) type

$$
U(C(t))=\int_{0}^{\infty} \frac{C(t)^{1-\theta}-1}{1-\theta} e^{-\rho t} d t,
$$

where $\rho$ is the rate of time preference and $\theta$ is the intertemporal elasticity of substitution. $C$ is a Cobb-Douglas type consumption aggregator defined over a continuum of final goods indexed by $z$ :

$$
\ln C(t)=\int_{z \in Z} \alpha \ln d(z, t) d z,
$$

with $d(z, t)$ denoting the consumption of product $z$ at time $t, Z$ being a measure of the set of available final products and $\alpha$ indicating the share of product $z$ in the consumption of $Z$ (identical $\forall z$ ). We drop the time argument $t$ in the following as long as this causes no confusion.

\subsection{Production Sector}

Suppose that final goods are produced from intermediates $Y_{K}$ and $Y_{L}$. Furthermore, suppose that the technology for final good $z$ can be described by the unit cost function

$$
c\left(p_{K}, p_{L}, z\right)=A p_{K}^{z} p_{L}^{1-z},
$$

where $p_{j}$ represents the prices of intermediate goods $Y_{j}(j=K, L)$, and $A$ is a parameter of the technology. Markets for all production factors, final goods and intermediate goods are perfectly competitive. Only final goods are internationally traded, and all factors of production are internationally immobile.

Intermediate goods are produced by using specialized machines according to the CEStype production functions

$$
Y_{K}=\left[\int_{0}^{N_{K}} x_{K}(n)^{1-\beta} d n\right]^{1 /(1-\beta)} \quad \text { and } \quad Y_{L}=\left[\int_{0}^{N_{L}} x_{L}(n)^{1-\beta} d n\right]^{1 /(1-\beta)},
$$

where $\beta \in(0,1)$, and $x_{j}(n)$ denotes the input of variety $n \in\left[0, N_{j}\right]$ of type $j$ machine in production of intermediate good $Y_{j}(j=K, L)$. $N_{j}$ measures the range of available machines of type $j$, i.e.: type- $j$ machines that have been invented in the past. Machines of each type $j$ are supplied by technology monopolists. In Section 3 we take the $N_{K}$ and $N_{L}$ as exogenously given. However, in Section 4 we explicitly model the 
innovation decisions, so that the values of $N_{K}$ and $N_{L}$ are endogenously determined in our model. For simplicity, we assume that all machines are fully used up in production. The technology for producing machines is supposed to be as follows:

$$
x_{K}(n)=K(n) \quad \text { and } \quad x_{L}(n)=L(n) .
$$

To complete the model and keep things simple, factor endowments of capital $K$ and labor $L$ are assumed to be given exogenously.

\section{Static Equilibrium}

A static equilibrium for given $\left(N_{K}, N_{L}\right)$ consists of (i) a set of prices for machines $\left(q_{K}(n), q_{L}(n)\right)$ that maximize profits of technology monopolists, (ii) machine demands from the intermediate producers $\left(x_{K}(n), x_{L}(n)\right)$ that maximize intermediate producers' profits, (iii) prices of intermediates $\left(p_{K}, p_{L}\right)$ that clear the market for intermediates, (iv) the range of final goods $(z)$ that is produced by a country, and (v) factor prices $\left(w_{K}, w_{L}\right)$ that clear factor markets.

Profit maximization of the producers of intermediates (taking as given the price of their product $p_{j}$, the prices of machines $q_{j}(n)$ and the range of available machines $N_{j}$ ) reads

$$
\max _{x_{j}(n)}\left\{p_{j} Y_{j}-\int_{0}^{N_{j}} q_{j}(n) x_{j}(n) d n: Y_{j}=\left[\int_{0}^{N_{j}} x_{j}(n)^{1-\beta} d n\right]^{1 /(1-\beta)}\right\}, \quad j=K, L .
$$

From the first-order condition we obtain the demand functions

$$
x_{j}(n)=\left[\frac{p_{j}}{q_{j}(n)}\right]^{1 / \beta} Y_{j}, \quad j=K, L .
$$

Demand for each variety of type $-j$ machine is increasing in the price of the respective intermediate good $j$ and in the demand for intermediate good $j$, but is decreasing in the price of the respective machine.

Technology monopolists take the demand for their machines in (7) and the factor price $w_{j}$ as given. Profit maximization of technology monopolists then reads

$$
\max _{q_{j}(n)}\left\{\left[q_{j}(n)-w_{j}\right] x_{j}(n): x_{j}(n)=\left[\frac{p_{j}}{q_{j}(n)}\right]^{1 / \beta} Y_{j}\right\}, \quad j=K, L .
$$

The first-order condition of the problem yields the well-known markup-pricing condition

$$
q_{j}(n)=\frac{w_{j}}{1-\beta}, \quad j=K, L
$$

J. Meckl, I. Savin

CEJEME 10: 75-100 (2018) 
Factor-Biased Technical Change and Specialization Patterns

Since (9) holds for all technology monopolists producing $j$-type machines, we obtain equilibrium machine prices as

$$
q_{j}(n)=\frac{w_{j}}{1-\beta} \equiv q_{j}, \quad j=K, L,
$$

and hence

$$
x_{j}(n)=\left[\frac{p_{j}}{q_{j}}\right]^{1 / \beta} Y_{j} \equiv x_{j}, \quad j=K, L .
$$

As a result of these symmetries, the production functions for intermediate goods (4) can be written as

$$
Y_{j}=N_{j}^{1 /(1-\beta)} x_{j}, \quad j=K, L .
$$

Given the technologies for producing machines, factor-market equilibrium conditions read

$$
K=\int_{0}^{N_{K}} x_{K}(n) d n, \quad L=\int_{0}^{N_{L}} x_{L}(n) d n .
$$

Due to the symmetry of machine producers, these conditions reduce to

$$
K=N_{K} x_{K}, \quad L=N_{L} x_{L} .
$$

Finally, by substituting for $x_{j}$ from (12), we obtain the supplies of intermediates:

$$
Y_{K}=N_{K}^{\beta /(1-\beta)} K \quad \text { and } \quad Y_{L}=N_{L}^{\beta /(1-\beta)} L .
$$

Thus, $N_{K}^{\beta /(1-\beta)} K$ and $N_{L}^{\beta /(1-\beta)} L$ can reasonably be interpreted as effective endowments of factors $K$ and $L$, respectively. Due to technological progress, physical factor endowments become more productive by increased differentiation in machines as measured by $N_{j}^{\beta /(1-\beta)}$. In the following, we will refer to $N_{j}^{\beta /(1-\beta)}$ as a measure of factor productivity. Note here, that if the country modeled is considered a developing country, and the other country in the two-country model is interpreted as the developed one, which we do in subsequent sections, one can expect $N_{j}^{*}>N_{j}$ in both sectors. However, as will become clear presently, only relative measures of the technology endowments matter in our model.

The equilibrium prices for intermediates can now be derived. Perfect competition on the markets for intermediates implies that prices have to be equal to unit costs. With our specification of the production functions in (4), and making use of the markup pricing in (10), the corresponding unit-cost functions are

$$
c_{j}\left(w_{j}\right)=\left[\int_{0}^{N_{j}}\left(\frac{w_{j}}{1-\beta}\right)^{(\beta-1) / \beta} d n\right]^{\beta /(\beta-1)}, \quad j=K, L .
$$

Equality of prices and unit costs then implies

$$
p_{K}=\frac{w_{K}}{1-\beta} N_{K}^{\beta /(\beta-1)} \quad \text { and } \quad p_{L}=\frac{w_{L}}{1-\beta} N_{L}^{\beta /(\beta-1)} .
$$




\subsection{The closed economy}

Before we turn to the two-country equilibrium, let us solve the equilibrium for a closed economy producing a range of final goods $z \in[\underline{z}, \bar{z}]$. From our Cobb-Douglas specification of consumer preferences in (2) we derive the market-clearing condition for final products as

$$
Y(z)=\alpha \frac{w_{L} L+w_{K} K}{p(z)}
$$

where $Y(z)$ denotes production of good $z$. The demands for intermediates are then obtained as

$$
Y_{K}=\int_{\underline{z}}^{\bar{z}} \frac{\partial c\left(p_{K}, p_{L}, z\right)}{\partial p_{K}} Y(z) d z \quad \text { and } \quad Y_{L}=\int_{\underline{z}}^{\bar{z}} \frac{\partial c\left(p_{K}, p_{L}, z\right)}{\partial p_{L}} Y(z) d z
$$

Substituting for $Y(z)$ by 16 and with prices equal to unit costs in the final goods sector, these demands can be written as

$$
Y_{K}=\int_{\underline{z}}^{\bar{z}} \alpha \frac{\partial c\left(p_{K}, p_{L}, z\right)}{\partial p_{K}} \frac{w_{L} L+w_{K} K}{c\left(p_{K}, p_{L}, z\right)} d z
$$

and

$$
Y_{L}=\int_{\underline{z}}^{\bar{z}} \alpha \frac{\partial c\left(p_{K}, p_{L}, z\right)}{\partial p_{L}} \frac{w_{L} L+w_{K} K}{c\left(p_{K}, p_{L}, z\right)} d z
$$

Making use of our specification of the unit-cost function in $\sqrt{3}$ we finally get the relative demand for intermediates as

$$
\frac{Y_{K}}{Y_{L}}=\frac{p_{L}}{p_{K}} \frac{\int_{\underline{z}}^{\bar{z}} z d z}{\int_{\underline{z}}^{\bar{z}}(1-z) d z} .
$$

Equilibrium on the market for intermediate goods can then be derived by equating relative supplies (from (14)) with relative demands from (17); applying equilibrium prices of intermediates according to (15), we obtain the factor-market-clearing condition as

$$
\frac{K}{L}=\frac{w_{L}}{w_{K}} \frac{\int_{\underline{z}}^{\bar{z}} z d z}{\int_{\underline{z}}^{\bar{z}}(1-z) d z} \equiv \frac{\phi(\underline{z}, \bar{z})}{\omega}
$$

with $\omega \equiv w_{K} / w_{L}$, which is the ratio of the rental rate of capital to the wage rate. The function $\phi$ has the derivatives $\partial \phi(\underline{z}, \bar{z}) / \partial \underline{z}>0$, and $\partial \phi(\underline{z}, \bar{z}) / \partial \bar{z}>0$.

There exists a unique value of the rental-wage ratio $\omega$ that clears factor markets. Since

J. Meckl, I. Savin 
Factor-Biased Technical Change and Specialization Patterns

$K / L$ is independent of $\omega$, and $\lim _{\omega \rightarrow 0} \phi(\underline{z}, \bar{z}) / \omega=\infty$ and $\lim _{\omega \rightarrow \infty} \phi(\underline{z}, \bar{z}) / \omega=0$, there exists a unique equilibrium value of $\omega$. Figure 1 illustrates the equilibrium on factor markets. The equilibrium value of $\omega$ depends positively on both $\underline{z}$ and $\bar{z}$. The intuition for this result is as follows: Note that due to our specification of technology for final products in (3), and together with (14), final goods are ordered according to their factor intensities such that capital intensity rises with the index $z$. Then, any increase in either $\underline{z}$ or in $\bar{z}$ raises the average capital intensity used in production of final goods and, therefore, raises the relative demand for capital at each value of $\omega$; with given factor supplies, this change in the relative demand for capital raises $\omega$.

Figure 1: Static equilibrium in the closed economy

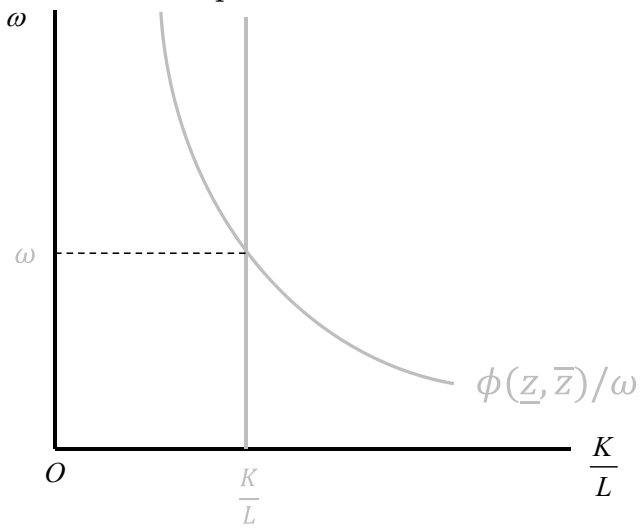

The closed-economy equilibrium is now completely determined. With $\omega$ determined by (18) and normalizing one factor price to unity, equilibrium prices for intermediate goods are determined by $(15)$, equilibrium machine prices by $(10)$ and final-goods' prices by $(3)$.

\subsection{Two country model with specialization in production}

The equilibrium in the two-country model is to be completed by determining the range of goods that is produced by each country. For that, we assume that the complete range of final goods produced in either country is given by the interval $[0,1]$. Suppose that the home country produces final products $z$ such that $z \in\left[0, z^{\prime}\right]$, while the foreign country produces final products $z$ such that $z \in\left[z^{\prime}, 1\right]$. This pattern of specialization implicitly assumes that the home country has a comparative advantage over the range of goods $z \in\left[0, z^{\prime}\right]$, whereas the foreign country has a comparative advantage over the range of $z \in\left[z^{\prime}, 1\right]$ goods. In what follows, we show that this pattern of comparative advantages arises from sufficiently great differences in relative effective factor supplies. Throughout the analysis, we assume that both countries 
have access to identical technologies for producing final goods (i.e.: both countries have the same cost function for producing $z$ ). However, both factor prices and prices of intermediates will differ due to complete specialization.

With a view to endogenizing index of the equilibrium threshold final-good that partitions the two countries into distinct ranges of product specialization, $\left[0, z^{\prime}\right]$ for the home country and $\left[z^{\prime}, 1\right]$ for the foreign one, we next prove Proposition 1 that plays a crucial role in the proof of further two propositions (2 and 33). Proposition 1 essentially says that for a difference in cross-country relative effective factor endowments bounded from below, a higher ratio of home to foreign country capital endowments entails a higher threshold commodity index, which by construction is produced more capital intensively.

We construct the proof in three steps, of which two are instructive in terms of explaining the functioning of our model and prove helpful in subsequent sections, and are thus presented below in some detail. The last one is of technical value instead of economic insights and is thus given in Appendix A. To this end, define factorproductivity adjusted relative factor endowments of the home and foreign country respectively as

$$
E=\frac{K}{L}\left(\frac{N_{K}}{N_{L}}\right)^{\beta /(1-\beta)} \text { and } E^{*}=\frac{K^{*}}{L^{*}}\left(\frac{N_{K}^{*}}{N_{L}^{*}}\right)^{\beta /(1-\beta)} .
$$

Proposition 1. For all $z_{1}^{\prime}, z_{2}^{\prime} \in[0,1]$ there exists $\gamma>0$ with $E^{*}-E>\gamma$ such that: $\left(K / K^{*}\right)_{2}>\left(K / K^{*}\right)_{1} \rightarrow\left(z_{2}^{\prime}>z_{1}^{\prime}\right)$, where $z_{1}^{\prime}$ and $z_{2}^{\prime}$ are capital-intensity-wise commodity specialization thresholds in a static equilibrium.

Proof

Step I proves that for all $p_{K} / p_{L}-p_{K}^{*} / p_{L}^{*}>0$ the home country produces $\left[0, z^{\prime}\right]$ and foreign country produces $\left.\left[z^{\prime}, 1\right]\right)$. Step II proves that if $E^{*}-E$ is bounded from below, then $p_{K} / p_{L}-p_{K}^{*} / p_{L}^{*}>0$. Step III, which is in Appendix A] completes the proof showing that the threshold $z^{\prime}$ increases in $K / K^{*}$ for given technologies.

Step I

In case of specialization, we first have to identify the threshold $z^{\prime}$ that determines the range of products produced in each country. With perfect competition on the markets for final goods, consumers buy final goods at the cheapest price:

$$
p(z)=\min \left\{c\left(p_{K}, p_{L}, z\right), c\left(p_{K}^{*}, p_{L}^{*}, z\right)\right\} .
$$

Hence, there exists at most one $z=z^{\prime}$, where both countries have identical unit costs in production:

$$
p_{K}^{z^{\prime}} p_{L}^{1-z^{\prime}}=p_{K}^{*} z^{\prime} p_{L}^{* 1-z^{\prime}} .
$$

In order to prove that assertion, define the function $\psi(z)$ as the ratio of unit costs:

$$
\psi(z) \equiv \frac{p_{K}^{z} p_{L}^{1-z}}{p_{K}^{*}{ }^{z} p_{L}^{*-z}} .
$$

J. Meckl, I. Savin 
Factor-Biased Technical Change and Specialization Patterns

Straightforward calculation gives:

$$
\frac{\psi^{\prime}(z)}{\psi(z)}=\ln \frac{p_{K}}{p_{L}}-\ln \frac{p_{K}^{*}}{p_{L}^{*}} .
$$

Suppose that $p_{K} / p_{L}>p_{K}^{*} / p_{L}^{*}$. Then, $\psi$ is an increasing function implying that $\psi\left(z^{\prime}\right)=1$. Of course, $z^{\prime} \in[0,1]$, since otherwise there would be no production at all in one of the countries.

Step II

From 15 we get:

$$
\frac{p_{K}}{p_{L}}=\omega\left(\frac{N_{K}}{N_{L}}\right)^{\beta /(\beta-1)} .
$$

Hence, for $p_{K} / p_{L}>p_{K}^{*} / p_{L}^{*}$ to hold (which we assumed in Step I), we require

$$
\omega\left(\frac{N_{K}}{N_{L}}\right)^{\beta /(\beta-1)}>\omega^{*}\left(\frac{N_{K}^{*}}{N_{L}^{*}}\right)^{\beta /(\beta-1)} .
$$

Substituting for relative factor prices according to 18 , we obtain

$$
\frac{K^{*}}{L^{*}}\left(\frac{N_{K}^{*}}{N_{L}^{*}}\right)^{\beta /(1-\beta)}>\frac{\phi\left(z^{\prime}, 1\right)}{\phi\left(0, z^{\prime}\right)} \frac{K}{L}\left(\frac{N_{K}}{N_{L}}\right)^{\beta /(1-\beta)} .
$$

Since $\phi\left(z^{\prime}, 1\right)>\phi\left(0, z^{\prime}\right),(24)$ is only fulfilled for sufficiently great differences in factorproductivity adjusted relative factor endowments:

$$
E^{*}>>E \text {. }
$$

Note that 24 implies $\omega>\omega^{*}$. Figure 2 illustrates the static equilibrium for sufficiently great differences in factor endowments.

Eventually, our endogenous determination of the range of available machines will show (see Section 4 ) that $N_{K} / N_{L}<N_{K}^{*} / N_{L}^{*}$ holds as long as $K / L<K^{*} / L^{*}$. This implies that our condition for the above discussed specialization pattern always holds in the long-run equilibrium of the model. The condition also holds in the instantaneous equilibrium as long as relative physical factor endowments do not change too drastically. Specifically: the condition holds as long as a one time capital inflow does not change the relative endowment ranking of the countries.

Step III

The final condition to completely describe the static equilibrium of the model is the trade-balance condition that requires the value of imports to equal the value of exports. With the home country specializing on $z \in\left[0, z^{\prime}\right]$, the trade-balance condition reads:

$$
\int_{0}^{z^{\prime}}\left(w_{L}^{*} L^{*}+w_{K}^{*} K^{*}\right) d z=\int_{z^{\prime}}^{1}\left(w_{L} L+w_{K} K\right) d z .
$$


Figure 2: Static equilibrium in the two-country model

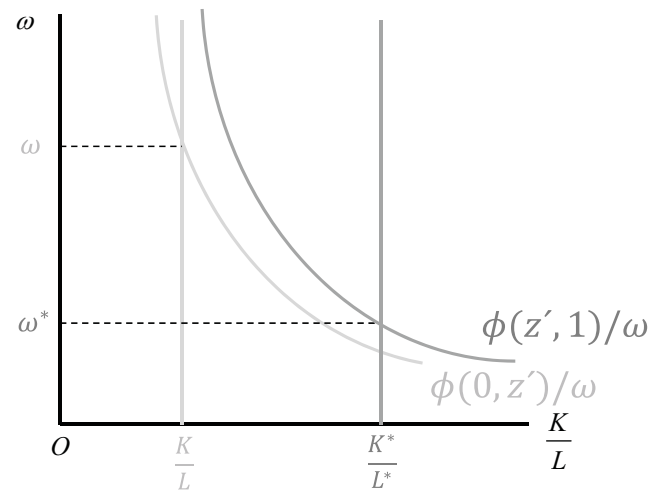

Since we do not include any constraints on the distribution of foreign trade income between the factors (see (2)), the variables in parentheses in $(26)$ are independent from $z^{\prime}$. Hence, the trade-balance condition can be presented as follows:

$$
\int_{0}^{z^{\prime}} d z / \int_{z^{\prime}}^{1} d z=\frac{w_{L} L+w_{K} K}{w_{L}^{*} L^{*}+w_{K}^{*} K^{*}},
$$

which is equivalent to:

$$
\frac{z^{\prime}}{1-z^{\prime}}=\frac{L+\omega K}{L^{*}+\omega^{*} K^{*}} \frac{w_{L}}{w_{L}^{*}} .
$$

We can now explicitly solve for the equilibrium value of $z^{\prime}$. Using (15) we can rewrite $P\left(z^{\prime}\right)=P *\left(z^{\prime}\right)$ as

$$
\frac{w_{L}}{w_{L}^{*}}=\left[\frac{\omega^{*}}{\omega}\left(\frac{N_{K}^{*}}{N_{K}} \frac{N_{L}}{N_{L}^{*}}\right)^{\beta /(\beta-1)}\right]^{z^{\prime}}\left(\frac{N_{L}^{*}}{N_{L}}\right)^{\beta /(\beta-1)} .
$$

As shown in Appendix A we prove that 27, 28 and (18) in Step II imply that

$$
z^{\prime}=\xi\left(\frac{K}{K^{*}}\right)
$$

is a monotonic increasing function. Hence, we have

$$
\forall\left(\frac{K}{K^{*}}\right)_{2}>\left(\frac{K}{K^{*}}\right)_{1} \rightarrow z_{2}^{\prime}=\xi\left(\frac{K}{K^{*}}\right)_{2}>\xi\left(\frac{K}{K^{*}}\right)_{1}=z_{1}^{\prime} .
$$

Proposition 1 thus endogenizes the index of the threshold commodity that divides between two countries the set of commodities that each will specialize in, and export.

J. Meckl, I. Savin 
Factor-Biased Technical Change and Specialization Patterns

This commodity-index $z^{\prime}$ increases from 0 to 1 as the capital-intensity of producing that commodity increases uniformly over the interval $\left[k_{\min }, k_{\max }\right]$ for real numbers $k_{\min }<k_{\max }$. It asserts that, given that the difference between the foreign and the home relative effective factor endowments is positive and bounded from below, or sufficiently large, then the greater is the home-to-foreign capital endowment ratio, the higher up on the capital-intensity spectrum the home country will produce and export commodities, in static equilibrium.

\section{Dynamic Equilibrium}

We can now solve the steady state of the dynamic equilibrium of the model and arrive at the following proposition.

Proposition 2. The incentives of technology monopolists to innovate in the $j$-type sector are proportional to the average intensity of that factor in the range of final goods currently produced in the economy; in other words, machine producers are better in innovating in the sector their host country is specializing in.

Proof

Profit-maximizing technology monopolists producing $j$-type machines generate more innovations in the sector $j(j=K, L)$, where they expect higher profits (higher prices for their machines). Using our results from the static equilibrium given by (14), profits of technology monopolists at each instant can be written as

$$
\pi_{K}=\beta \frac{w_{K}}{1-\beta} \frac{K}{N_{K}} \quad \text { and } \quad \pi_{L}=\beta \frac{w_{L}}{1-\beta} \frac{L}{N_{L}} .
$$

With short-run equilibrium values of the relative factor price determined by (18), relative profits can eventually be written as

$$
\frac{\pi_{K}}{\pi_{L}}=\left(\frac{N_{K}}{N_{L}}\right)^{-1} \phi(\underline{z}, \bar{z}) .
$$

With respect to the production of machines we apply, in order to differentiate the impact of $z^{\prime}$ on technological progress in the two countries, state-dependent (also called knowledge-driven) production function of new machines (see Acemoglu (2002) and Romer (1990) for discussion) as follows:

$$
\dot{N}_{i}=\eta_{i} N_{i}^{(1+\delta) / 2} N_{j}^{(1-\delta) / 2} S_{i}, \quad i, j \in(L, K), \quad i \neq j,
$$

where $S \geq S_{L}+S_{K}$ is a limited R\&D staff (scientists) that cannot be extended and $\delta \in[0,1]$ measures the degree of state dependence. It can be shown that when $\delta=0$, both sectors equally benefit from research in one of them, further results are similar to 
the ones stated in Appendix B However, if $\delta>0$, results can vary significantly. Thus, for $\delta=1$ improvements in labor intensive machines make future innovations in this industry cheaper without any effect on the other sector. In this paper we argue that both $\delta=0$ and $\delta=1$ are extreme cases. In the context of the economic globalization it is both unlikely that two sectors do not jointly benefit from technological progress in one of them $(\delta \neq 1)$ or make an equal use of technological improvements made in any of the sectors $(\delta \neq 0)$. Alternatively, in Appendix B we also consider a simpler production function á la Rivera-Batiz and Romer (1991), where new machines can be produced simply by increase in $\mathrm{R} \& \mathrm{D}$ spending. The result of the exercise also supports the intuition of the model stated so far and serves as a benchmark. In steady state, $N_{K}$ and $N_{L}$ grow at the same rate. This implies the technologymarket-clearing condition

$$
\eta_{L} N_{L}^{\delta} \pi_{L}=\eta_{K} N_{K}^{\delta} \pi_{K}
$$

From 33 we get relative profits as

$$
\frac{\pi_{K}}{\pi_{L}}=\frac{\eta_{L}}{\eta_{K}}\left(\frac{N_{L}}{N_{K}}\right)^{\delta} .
$$

With 31 we solve for the steady-state ratio of $N_{K}$ and $N_{L}$ as

$$
\frac{N_{K}}{N_{L}}=(\eta \phi(\underline{z}, \bar{z}))^{1 /(1-\delta)}
$$

where $\eta \equiv \eta_{K} / \eta_{L}$. From the properties of the function $\phi$ in 18$)$ we get: the higher the average capital intensity of the range of final goods produced in the economy, the higher the incentives to innovate in type $K$ machines, and the higher the long-run ratio $N_{K} / N_{L}$.

Specifically, in the equilibrium of the two-country model with the home country specializing on final products $z \in\left[0, z^{\prime}\right]$, while the foreign country specializes on final products $z \in\left[z^{\prime}, 1\right]$, the long-run ratio $N_{K} / N_{L}$ is given by

$$
\frac{N_{K}}{N_{L}}=\left(\eta \phi\left(0, z^{\prime}\right)\right)^{1 /(1-\delta)}<\frac{N_{K}^{*}}{N_{L}^{*}}=\left(\eta \phi\left(z^{\prime}, 1\right)\right)^{1 /\left(1-\delta^{*}\right)} .
$$

The result in 35 with $\delta=\delta^{*}$ is just what we supposed for our analysis of the static equilibrium. For different $\delta$ 's (35) seen as an equality, implicitly determines an upper bound for $\delta$. Notice that the equilibrium stated above is stable. If equation (33) is not satisfied, machine producers concentrate only on the sector that is more profitable to produce in. Since $\pi_{K} / \pi_{L}$ is decreasing in $N_{K} / N_{L}$ (see (31) the system always returns to the steady state: if $N_{K} / N_{L}$ is higher than in (34), monopolists produce only labor-substituting machines until the system equalities are satisfied, and vice versa.

J. Meckl, I. Savin 
Factor-Biased Technical Change and Specialization Patterns

\section{Capital Flows and Dynamic CAs}

We can now apply our model to the analysis of dynamics of comparative advantages associated with an inflow of capital. Assume, like in Section 3 that the foreign country is abundant in capital (like industrialized countries), while the home country is labor abundant (like developing countries or economies in transition).

Provided that differences in relative effective factor endowments are sufficiently large, in the initial equilibrium we have: (i) $\omega>\omega^{*}$, (ii) $N_{K} / N_{L}<N_{K}^{*} / N_{L}^{*}$, and (iii) the home country has $\mathrm{CA}$ for final products $z \in\left[0, z^{\prime}\right]$, the foreign country for $z \in\left[z^{\prime}, 1\right]$. Suppose now that capital flows into the home country (caused by the differences in relative factor prices). However, we do not assume fully integrated capital markets with full equalization of factor prices, since this is supported by Blum (2010) testing factor price equalization theorem on industry-level data for 27 developed and developing countries over 1973-1990 and finding no support.. If that were the case, capital-market integration would result in full diversification of the final-goods sector with the well-known indeterminacy of production precluding any analysis of CAs (cf. Dornbusch et al. (1980)). Given the complexity of the model, including differences in factor endowments and technologies between countries, and endogenous technical change, we simplify our analysis to a one-time capital inflow.

Proposition 3. Due to a one-time capital movement from a capital-abundant to a capital-scarce country, three major effects distinct in time are set in force: in the short-run a) the price effect on the rental rate of capital adjusts prices to the new supply of capital, while b) the capital recipient expands the spectrum of goods produced according to Proposition 1: in the long-run, c) technology monopolists adjust their production to the new specialization pattern according to Proposition 2 thus triggering the specialization threshold further up.

Proof

As capital flows into the home country, we observe a decline in $\omega$ and an increase in $\omega^{*}$ for given $z^{\prime}$ (with given $N_{j}$ 's) in the short-run, i.e.: for given pattern of specialization. See left plot in Figure 3 for an illustration (shifts from $\omega_{0}$ to $\omega_{1}$ and $\omega_{0}^{*}$ to $\omega_{1}^{*}$, respectively). Therefore, for given technologies, the pattern of specialization adjusts. According to Proposition 1, the capital flow from the capital-abundant country to the labor-abundant one generates a change in the pattern of specialization with the latter country specializing on a larger spectrum of final goods and the former country producing a narrower range of goods. As $z^{\prime}$ rises (let us denote the shift on the right plot in Figure 3 from $z_{0}^{\prime}$ to $z_{1}^{\prime}$ with $z_{1}^{\prime}>z_{0}^{\prime}$ ), relative factor prices in both countries shift upwards (from $\omega_{1}$ to $\omega_{2}$ and $\omega_{1}^{*}$ to $\omega_{2}^{*}$ ). This is due to the property of the function $\phi(\underline{z}, \bar{z})$ described. Thus, in the foreign country, which exports capital, $\omega^{*}$ rises both due to the capital outflow and reduction in the range of final goods produced in the economy (increase in the average capital intensity). In contrast, in 
the home country $\omega$ firstly falls due to the capital inflow, but then rises due to the increase of capital intensity used in production. However, as a whole $\omega$ decreases since the capital inflow is the major triggering factor of this dynamics, and the incentive for further capital transfer (difference in the capital income between countries) has to decrease. In the long-run, the shift in $z^{\prime}$ creates incentives for further innovations $\left(\dot{N}_{j}\right)$, thereby magnifying the change in $z^{\prime}$ and factor-price ratios $\omega$ and $\omega^{*}$. Thus, the size of the capital inflow is assumed to be substantial enough to cause the dynamics, which can be justified, e.g., considering the large FDI inflow to the CEE countries over the last two decades (Wziatek-Kubiak and Winek 2005).

Figure 3: Comparative statics in the two-country model
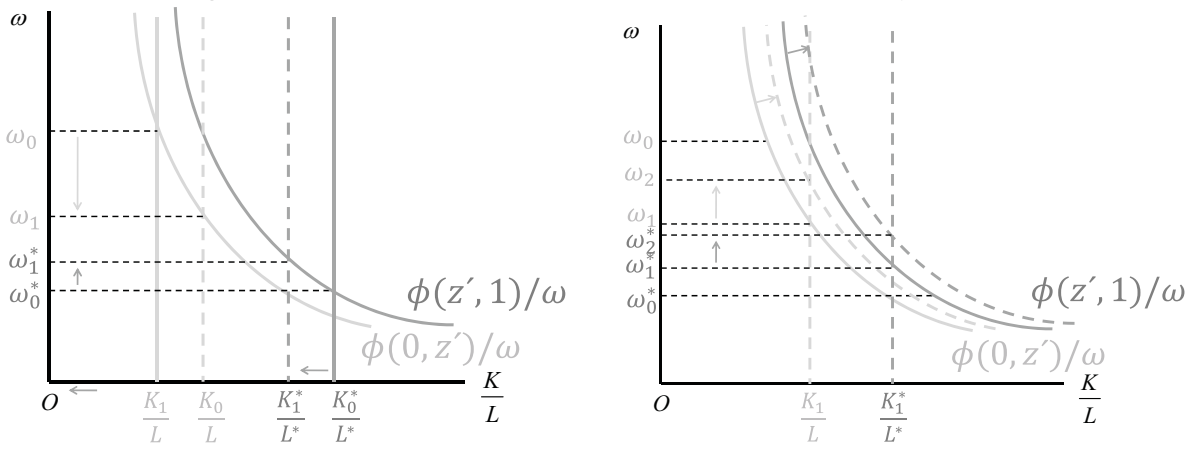

Due to the increase in the cutoff value $z^{\prime}$, technology monopolists in both countries get an incentive to innovate in the sector of capital (see (34)). Hence, both $N_{K} / N_{L}$ and $N_{K}^{*} / N_{L}^{*}$ rise and trigger the relative factor prices $p_{K} / p_{L}$ in both countries down (this effect is denoted as the 'market size effect'):

$$
\frac{p_{K}}{p_{L}}=\omega(\eta \phi(\underline{z}, \bar{z}))^{\beta /[(\beta-1)(1-\delta)]} .
$$

Based on equation (36) we can differentiate between the incentives for technology monopolists to innovate in the sector of type $K$ machines as long as $\delta \in(0,1)$. In fact, if $\delta=0$ equations (33-34) can be reduced back to the lab equipment specification in Appendix B In contrast, if $\delta=1$ the stability condition is not satisfied (Section 4). Hence, no stable equilibrium can be achieved.

Having in mind the classification of industrial policies introduced by Ergas (1987) and further developed by Cantner and Pyka (2001), we assume $\delta^{*} \rightarrow 0$ for the industrialized country and $\delta \rightarrow 1$ for the developing economy. The main reason for this is the fact that developing countries trying to catch-up the industrialized ones are more likely to adopt the so-called mission-oriented technology policy consisting in focusing own resources on applied research for a handful of technologies and key 
Factor-Biased Technical Change and Specialization Patterns

players (technology monopolists) performing the in-house R\&D. Just as an opposite, more industrialized countries, tend to adopt a diffusion-oriented technology policy emphasizing the role of basic research (with a wide range of application not being limited to one sector or factor of production) and indirect stimulation mechanisms such as R\&D employment subsidies, venture capital and knowledge transfer. While the former shall provide the opportunity of a rapid technology accumulation in a given sector, the latter type of policy concentrates on transferring knowledge and allows for self-regulation of the market for innovations. Cantner and Pyka (2001) demonstrate empirically how Germany moved from mission- to diffusion-oriented policy in the period between 1975 to 1996. Lee and Lim (2001) and Koh and Wong (2005) demonstrate that the mission-oriented policy has been typical for South Korea and Singapore, respectively. Of course, one shall not forget that proclaiming the policy does not imply succeeding in it. For example, Castaldi and Dosi (2010) contrasts Far Eastern and Latin American countries stressing the role of patterns of information distribution and interaction, which resulted in different learning capabilities of individuals and organization, and also very different growth paths over time.

In comparison to the results from the lab equipment model, an important distinction here is the rate of factor-biased technical change (FBTC). Because of $(1-\delta)$ in $(3436)$, the technological progress in capital intensive goods and CAs in this sector are both amplified depending on $\delta$. Therefore, benefits both from technology improvements and price reductions are potentially higher for the home country than for the foreign one (that translates in a further increase in $z^{\prime}$ in the long-run). This finding explains the convergence effect in productivity $\left(N_{K} / N_{L} \rightarrow N_{K}^{*} / N_{L}^{*}\right)$ one observes in the CEE countries over the last decades accompanied by the remarkable growth in CAs in capital intensive goods (Zaghini 2005).

Remember, in 32 we specified $S$ as a limited resource. Hence, for a sustained growth we need other factors $\left(N_{L}\right.$ and $\left.N_{K}\right)$ to become more productive over time or, in other words, accumulate these factors. This is by all means a more time-consuming process than the one presented in the lab equipment model from Rivera-Batiz and Romer (1991) where new machines can be produced simply by increase in R\&D spending. Therefore, impacts of the price and the market size effects must be differentiated in time. While the price effect comes into force quickly, the market size effect follows with a time lag that is dependent, e.g, on the distance to frontier for each particular country and on the inefficiencies on the market of technology monopolists in those countries.

\section{Discussion and Conclusion}

David Ricardo's theory of comparative advantage is one of the most important explanations of why a country exports one commodity rather than another - based on technological differences across countries. The Heckscher-Ohlin explanation relies 
Jürgen Meckl and Ivan Savin

on international relative factor endowment differences. Since these explanations take technological or factor-endowment differences as exogenously given, they constitute atemporal, static theories. However, economic history also reveals countries acquiring comparative advantage over time in hitherto imported commodities. This phenomenon falls squarely in the domain of dynamic processes. How does this come about, and by what kind of processes? These are important questions, which have received considerable attention, in the contributions of Krugman (1979), Grossman and Helpman (1993), Helpman (1993), Acemoglu (1998, and 2002), Antràs (2005) and more recently Acemoglu et al. (2012), among others. However, these contributions confine their analysis to structural adjustment within given specialization regimes; so their discussion of dynamic comparative advantage does not account for changes in the range of products produced.

The main assumption of the model stated that allows us to reveal factors directing a technological bias between sectors is the assumption on technology monopolists comparing expected profits from their investments in different technologies. A similar intuition has the concept of prospective comparative advantages (PCAs) that forecast CA dynamics in transition economies (see Savin and Winker (2009)). The PCAs are based on differences in relative prices of products in different countries. Assuming price convergence in the long-run, PCAs identify potential CAs in industries, where final goods are undervalued in comparison to the international price level. Hence, in the future these industries are potentially profitable for investors. In a similar way, the FBTC concept 'directs' technological progress towards industries expecting factor inflow and, consequently, an increase in the intensity of its employment (Section 4). In fact, there is a large body of empirical evidence that the CA dynamics is driven by the competitive advantages measured by, e.g, unit labor costs, R\&D intensity, real exchange rates (Wziatek-Kubiak and Winek 2005) or technological capabilities proxied by, e.g., accumulated patent stocks (Soete 1987, Petralia et al. 2017). An important distinction of the PCA is that it encompasses more information on the competitiveness of goods and distinguishes between industries of a particular economy, 'substituting' the indicators mentioned. In contrast, our model does not 'substitute', but 'complements' the index. Practically, the model explains the behavior of technology monopolists that produce innovations in capital intensive technologies in the CEE countries, strengthening CA formation in respective industries. However, technical change biases alone should not be considered as sufficient to benefit from CAs. Otherwise, we would observe CAs in the EU new member states on a much larger variety of goods. There must be a different factor 'allowing' transition economies to form CAs towards their trade partners. The simple reason for this is the fact that we need to account not only for the technological progress in the home country (with capital inflow), but also for the state of technology in the foreign economy (exporting capital) as well as for other factors, responsible for CAs between countries, including, e.g., scale of production, consumption preferences. Therefore, for transition economies a primary condition for CAs to arise is a presence of unrealized CAs assuring that 
Factor-Biased Technical Change and Specialization Patterns

they potentially have an advantage towards other economies in a particular sector. And a good instrument available to forecast the unexploited advantages is the PCA index.

In our model we refer to a well-known discussion in the theory of industrial organization: should countries stimulate innovations in high technological industries or in sectors with strongest CAs (see, e.g., Rodriguez-Clare (2005)). Considering high technological industries as the ones with highest 'Marshallian externalities' (MEs), which present benefits from KSs between companies in the same (or related) industries, Rodriguez-Clare (2005) identifies two constraints for policies promoting industries with strongest MEs. First, in contrast to CAs, MEs are not an intrinsic feature of particular industries. Since MEs (as well as FBTCs) depend on firms' innovative activity and are stochastic in their nature, no 'guaranteed' benefits from these processes exist. Second, even if an industry exhibits strong MEs, benefits generated from these externalities can be also attributed to another (foreign) country specializing in this industry neutralizing benefits for the home country.

As a result, a general approach for countries stimulating their economic growth is to promote industries with natural CAs and not those with stronger MEs. For the least developed countries this simply means that they should stimulate predominantly agriculture and mining industries. Fortunately, based on the insights from our model transition economies, as e.g., CEE countries have a better choice. However, realization of this scenario is not as straightforward, but requires the inflow of scarcer factor $(K)$. Thus, according to our model, CAs can be stimulated with no artificial price distortions or other potentially inefficient public interventions. Instead, for transition economies to attract FDI, in parallel with (already available) natural resources and relatively cheap labor force, policy liberalization (including, transparent regulatory framework, ease of market entry and exit) and political stability are of great importance (Mizanur Rahman 2010, Boschma and Capone 2015).

Furthermore, due to the form of production functions specified in (4) and the assumption of state dependent $\mathrm{R} \& \mathrm{D}(32)$, the rate of economic growth of any particular economy is crucially dependent on accumulation of technologies $\left(N_{i}\right)$ that increase factor efficiency. Since machine-producers are assumed to be monopolists, it is important to consider the problem of potential market inefficiency resulting in a low rate of investments in $\mathrm{R} \& \mathrm{D}$. There is a long discussion in the theory of industrial organization on whether competitive pressure induces or reduces innovative output of companies. During the last decade, the idea of an inverse ' $\mathrm{U}$-curve' dependence of innovative activities on the competition intensity has become the prevailing concept (see Aghion et al. (2005) and Bucci and Parello (2009)). It is empirically confirmed that in contrast to monopoly, competition raises incentives to innovate, but an excessive competitive pressure damages innovative performance. Therefore, a balanced public regulation policy for developing economies is required to stimulate national 'technology monopolists' (empirical evidence supporting this claim for South Korea and China can be found in Lee and Lim (2001) and Yu et al. (2015), 
respectively).

To sum up, in this paper we integrate technology-based with factor endowment-based views on trade in modeling effects resulting from capital-market integration. We demonstrate that the model suggested effectively explains the capital-biased technical change observed in a number of developing and transition economies over the last decades. Furthermore, accounting for the state-dependent R\&D processes, we can differentiate in time the effects of capital inflow on specialization patterns explaining the time lags in $\mathrm{CA}$ responses observed empirically. In addition, a parallel with an empirical PCA index and a series of measures for transition countries to realize their potential comparative advantages are discussed.

To keep the exposition simple, this paper has a number of simplifying assumptions. An obvious generalization is to introduce CES-type production functions and allow for factors and machines to compliment each other in production. So far, a specific case of technological process was considered. Another interesting direction for future research would be to endogenize the rate of spillovers $(\delta)$. Finally, an important field for future research is an empirical assessment of the effects resulting from the capitalmarket integration in developing countries. In particular, having industry-based data, one could measure the effect of capital inflow on R\&D intensity and, consequently, on CA formation quantitatively. Hitherto, to the best of our knowledge, only the effect of FDI on productivity level (measured either as labor or total factor productivity) was considered in the literature (see among others, Holland and Pain (1998), Barrell and Holland (2000), Smarzynska Javorcik (2004), Bijsterbosch and Kolasa (2010)).

\section{Acknowledgements}

Thanks are due to participants of the 13th workshop on international economic relations in Göttingen and colleagues from the DFG program 'Economics of Innovative Change' in Jena for their constructive comments that helped to improve the paper. A special thanks to Daniel Trefler and Nadeem Naqvi for their valuable advices with regard to motivation for the relevance of our model and also to J. Peter Neary and Jagdish Bhagwati for helpful comments. IS acknowledges support from the German Science Foundation (DFG RTG 1411), the Helmholtz Association (HIRG0069), Projex CSES, Initiative d'Excellence, Université de Strasbourg and RFBR grant Nr. 18-010-01190.

\section{References}

[1] Acemoglu, D. (1998). Why do new technologies complement skills? directed technical change and wage inequality. Quarterly Journal of Economics 113(4), 1055-1089.

J. Meckl, I. Savin 
Factor-Biased Technical Change and Specialization Patterns

[2] Acemoglu D. (2002). Directed technical change. Review of Economic Studies 69, 781-809.

[3] Acemoglu D., Gancia G. and Zilibotti F. (2012). Offshoring and directed technical change. Technical Report 18595. NBER Working Paper Series.

[4] Aghion P., Bloom N., Blundell R., Griffith R. and Howitt P. (2005). Competition and innovation: An inverted U relationship. Quarterly Journal of Economics 120, 701-728.

[5] Antràs P. (2005). Incomplete contracts and the product cycle. American Economic Review 95(4), 1054-1073.

[6] Barrell R. and Holland D. (2000). Foreign direct investment and enterprise restructuring in Central Europe. Economics of Transition 8(2), 477-504.

[7] Bijsterbosch M. and Kolasa M. (2010). FDI and productivity convergence in Central and Eastern Europe - an industry-level investigation. Review of World Economics 145(4), 689-712.

[8] Blum B. (2010). Output, endowments, and the bias of directed innovation. Review of Economic Studies 77(2), 534-559.

[9] Boschma R. and Capone HG. (2015). Institutions and diversification: Related versus unrelated diversification in a varieties of capitalism framework. Research Policy 44(10), 1902-1914.

[10] Bucci A. and Parello C.P. (2009). Horizontal innovation-based growth and product market competition. Economic Modelling 26(1-2), 213-221.

[11] Cantner U. and Pyka A. (2001). Classifying technology policy from an evolutionary perspective. Research Policy 30(5), 759-775.

[12] Castaldi C. and Dosi G. (2010). Technical change and economic growth: Some lessons from secular patterns and some conjectures on the current impact of ICT technology. [in:] Innovation and Economic Development. The Impact of Information and Communication Technologies in Latin America (Cimoli M., Hofman A.A. and Mulder N. [eds.]). Edward Elgar Publishing.

[13] Dornbusch R., Fisher S. and Samuelson P.A. (1980). Heckscher-Ohlin trade theory with a continuum of goods. Quarterly Journal of Economics 95(2), 203224 .

[14] Ergas H. (1987). The importance of technology policy. [in:] Economic Policy and Technological Performance (Dasgupta P. and Stoneman P. [eds.]). Cambridge University Press. Cambridge. 
[15] Frensch R. and Gaucaite Wittich V. (2009). Product variety and technoical change. Journal of Development Economics 88, 242-257.

[16] Grossman G.M. and Helpman E. (1993). Innovation and Growth in the Global Economy. The MIT Press. Cambridge, Mass.

[17] Helpman E. (1993). Innovation, imitation, and intellectual property rights. Econometrica 61(6), 1247-1280.

[18] Holland D. and Pain N. (1998). The diffusion of innovations in Central and Eastern Europe: A study of the determinants and impact of foreign direct investment. Technical Report 137. NIESR Discussion Paper. London.

[19] Koh W.T.H. and Wong P.K. (2005). Competing at the frontier: The changing role of technology policy in Singapore's economic strategy. Technological Forecasting and Social Change 72(3), 255-285.

[20] Krugman P. (1979). A model of innovation, technology transfer, and the world distribution of income. Journal of Political Economy 87(2), 253-266.

[21] Lee K. and Lim C. (2001). Technological regimes, catching-up and leapfrogging: findings from the Korean industries. Research Policy 30(3), 459-483.

[22] Mizanur Rahman M. (2010). Factors attracting foreign direct investment (FDI) in a country. The Financial Express Editorial. http://www. thef inancialexpress .bd.com/more.php?news_id=97499\&date=2010-04-13 Accessed 30 March 2011.

[23] Neary J.P. (1985). International factor mobility, minimum wage rates, and factorprice equalization: A synthesis. Quarterly Journal of Economics 100(3), 551-570.

[24] Petralia S., Balland P.-A. and Morrison A. (2017). Climbing the ladder of technological development. Research Policy 46(5), 956-969.

[25] Puga D. and Trefler D. (2010). Wake up and smell the ginseng: International trade and the rise of incremental innovation in low-wage countries. Journal of Development Economics 91(1), 64-76.

[26] Rivera-Batiz L.A. and Romer P.M. (1991). Economic integration and endogenous growth. Quarterly Journal of Economics 106(2), 531-555.

[27] Rodriguez-Clare A. (2005). Clusters and comparative advantage: Implications for industrial policy. Journal of Development Economics 82(1), 43-57.

[28] Romer P.M. (1990). Endogenous technological change. Journal of Political Economy 98(5), 71-102.

J. Meckl, I. Savin 
Factor-Biased Technical Change and Specialization Patterns

[29] Savin I. and Winker P. (2009). Forecasting Russian foreign trade comparative advantages in the context of a potential WTO accession. Central European Journal of Economic Modelling and Econometrics 1(2), 111-138.

[30] Sen A. (2008). The discipline of economics. Economica 75(300), 617-628.

[31] Smarzynska Javorcik B. (2004). Does foreign direct investment increase the productivity of domestic firms? In search of spillovers through backward linkages. American Economic Review 94(3), 605-627.

[32] Soete L. (1987). The impact of technological innovation on international trade patterns: The evidence reconsidered. Research Policy 16(2-4), 101-130.

[33] Trefler D. (1993). International factor price differences: Leontief was right! Journal of Political Economy 101(6), 961-987.

[34] Trefler D. (1995). The case of the missing trade and other mysteries. American Economic Review 85(5), 1029-1046.

[35] Wziatek-Kubiak A. and Winek D. (2005). Changes in competitive advantages of transition economies: Measurement and factors. [in:] Structural Change and Exchange Rate Dynamics (Wziatek-Kubiak A. and Welfens P.J.J. [eds.]). pp. 9-33. Springer Heidelberg.

[36] Yu X., Dosi G., Lei J. and Nuvolari A. (2015). Institutional change and productivity growth in China's manufacturing: the microeconomics of knowledge accumulation and "creative restructuring". Industrial and Corporate Change $24(3), 565-602$.

[37] Zaghini A. (2005). Evolution of trade patterns in the new EU member states. Economics of Transition 13, 629-658.

[38] Zhu S.C. (2007). On the welfare implications of Southern catch-up. Economics Letters 94(3), 378-382.

[39] Zhu S.C. and Trefler D. (2005). Trade and inequality in developing countries: a general equilibrium analysis. Journal of International Economics 65(1), 21-48.

\section{A Derivation of the condition for $z^{\prime}$ (Proposition 1)}

This appendix shows how the specialization threshold $z^{\prime}$ is related to factor endowments. From (27) follows that

$$
\frac{z^{\prime}}{1-z^{\prime}}=\frac{w_{L}}{w_{L}^{*}} \frac{L}{L^{*}} \frac{1+\omega \frac{K}{L}}{1+\omega^{*} \frac{K^{*}}{L^{*}}} .
$$


Substituting for $w_{L} / w_{L}^{*}$ by (28), we obtain

$$
\frac{z^{\prime}}{1-z^{\prime}}=\left[\frac{\omega^{*}}{\omega}\left(\frac{N_{K}^{*}}{N_{K}} \frac{N_{L}}{N_{L}^{*}}\right)^{\beta /(\beta-1)}\right]^{z^{\prime}}\left(\frac{N_{L}^{*}}{N_{L}}\right)^{\beta /(\beta-1)} \frac{L}{L^{*}} \frac{1+\omega \frac{K}{L}}{1+\omega^{*} \frac{K^{*}}{L^{*}}} .
$$

Evaluating 18 for the two countries we get

$$
\omega \frac{K}{L}=\frac{\int_{0}^{z^{\prime}} z d z}{\int_{0}^{z^{\prime}} 1-z d z}=\frac{z^{\prime}}{2-z^{\prime}} \quad \text { and } \quad \omega^{*} \frac{K^{*}}{L^{*}}=\frac{\int_{z^{\prime}}^{1} z d z}{\int_{z^{\prime}}^{1} 1-z d z}=\frac{1-z^{\prime 2}}{\left(1-z^{\prime}\right)^{2}} .
$$

From (37) and 39 we derive the inverse of the condition for $z^{\prime}$ :

$$
\begin{aligned}
\frac{K^{*}}{K}= & \frac{\left(1+z^{\prime}\right)}{\left(1-z^{\prime}\right)}\left(\frac{1}{z^{\prime}}\right)^{\left(1+z^{\prime}\right) / z^{\prime}}\left(\frac{1}{2-z^{\prime}}\right)^{\left(1-z^{\prime}\right) / z^{\prime}}\left(1-z^{\prime}\right)^{2 / z^{\prime}}\left(\frac{N_{K}^{*}}{N_{K}}\right)^{\beta /(\beta-1)} \\
& \cdot\left[\left(\frac{N_{L}^{*}}{N_{L}}\right)^{\beta /(\beta-1)} \frac{L}{L^{*}}\right]^{\left(1-z^{\prime}\right) / z^{\prime}} .
\end{aligned}
$$

Remembering that our specialization pattern can be rationalized iff

$$
\begin{aligned}
\frac{K}{L}\left(\frac{N_{K}}{N_{L}}\right)^{\beta /(1-\beta)}<< & \frac{K^{*}}{L^{*}}\left(\frac{N_{K}^{*}}{N_{L}^{*}}\right)^{\beta /(1-\beta)} \Leftrightarrow \\
& \Leftrightarrow \frac{K^{*}}{K}\left(\frac{N_{K}^{*}}{N_{K}}\right)^{\beta /(1-\beta)}>>\frac{L^{*}}{L}\left(\frac{N_{L}^{*}}{N_{L}}\right)^{\beta /(1-\beta)},
\end{aligned}
$$

we can show that $z^{\prime}$ is monotonously increasing in $K / K^{*}$.

For that purpose, let us rewrite 40 as follows:

$$
\kappa=\underbrace{\frac{\left(1+z^{\prime}\right)}{\left(1-z^{\prime}\right)}\left(\frac{1}{z^{\prime}}\right)^{\left(1+z^{\prime}\right) / z^{\prime}}\left(\frac{1}{2-z^{\prime}}\right)^{\left(1-z^{\prime}\right) / z^{\prime}}\left(1-z^{\prime}\right)^{2 / z^{\prime}}}_{g\left(z^{\prime}\right)} \underbrace{\varphi^{\left(1-z^{\prime}\right) / z^{\prime}}}_{h\left(z^{\prime}\right)}
$$

denoting $K^{*} / K\left(N_{K}^{*} / N_{K}\right)^{\beta /(1-\beta)}$ with $\kappa$ and $\left(N_{L} / N_{L}^{*}\right)^{\beta /(1-\beta)} L / L^{*}$ with $\varphi$. Thus, we need to show that $\kappa$ is monotonously decreasing in $z^{\prime} \forall \varphi$ as long as 41) holds.

While $g\left(z^{\prime}\right)$ in 42 is a monotonously decreasing function in $z^{\prime}$, the behavior of the complete function is dependent on the value of $\varphi$ in $h\left(z^{\prime}\right)$. In particular, the r.h.s. of (42) remains monotonously decreasing as long as $\varphi$ is greater than a critical value of about 0.21 while it shows a spike in its performance otherwise. The properties of 42 are illustrated in Figure 4 for different $\varphi$ values. Important, however, is that $\forall \varphi<0.21$ the ambiguity in $z^{\prime}$ we obtain (as on the right plot of Figure 4) is always for values below 1 in $\kappa$, i.e. in the interval, where our model is not applicable (without

J. Meckl, I. Savin

CEJEME 10: 75-100 (2018) 
sufficiently great differences in relative effective factor endowments) since from (41) $\kappa>>1 / \varphi$ must hold. Hence, in accord with our assumptions $z^{\prime}$ is monotonously increasing in $K / K^{*}$ :

$$
\xi^{\prime}\left(K / K^{*}\right)>0
$$

for the relevant set of parameter values.

Figure 4: Interrelationship between $z^{\prime}$ and $\kappa$ for different $\varphi$
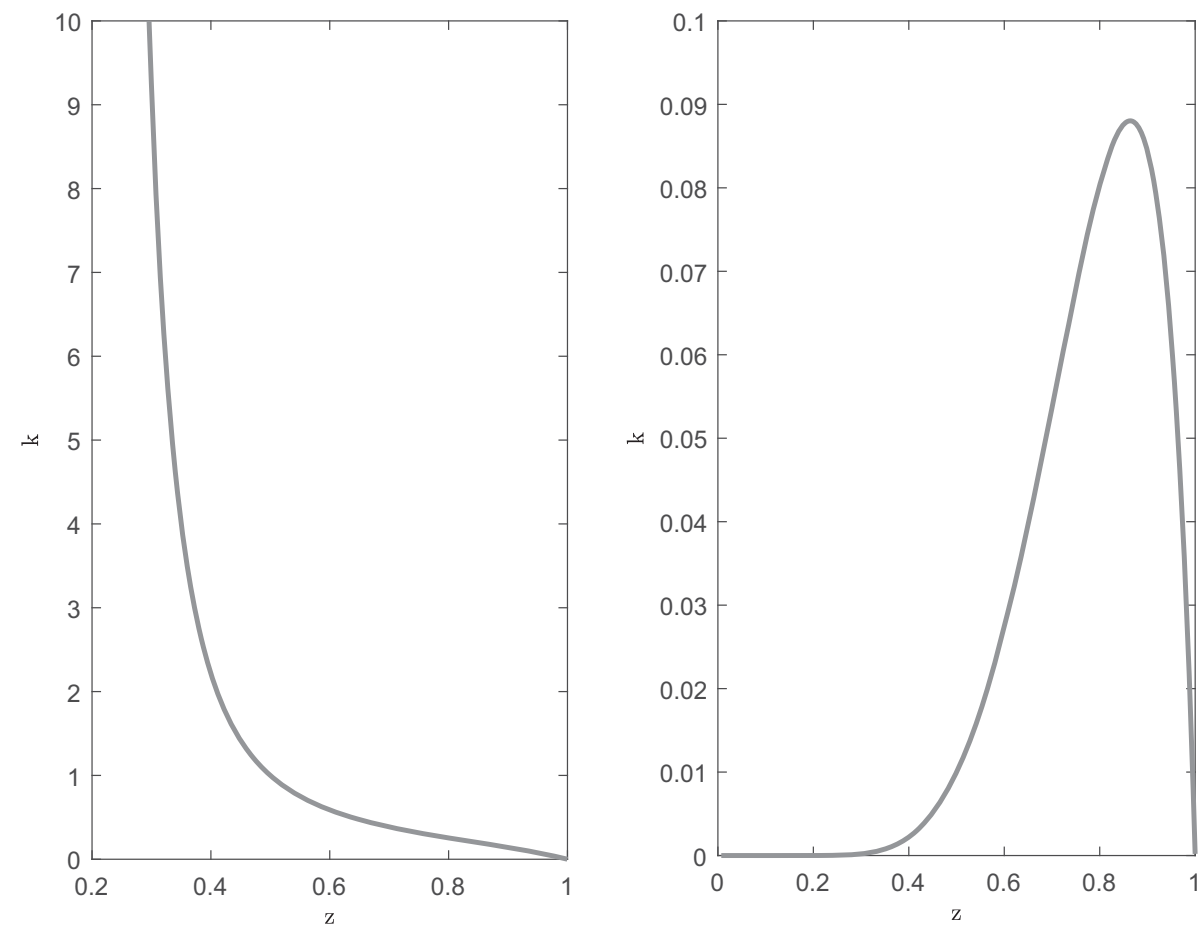

\section{B Lab equipment specification of innovation}

Alternatively, we also considered the lab equipment specification of Rivera-Batiz and Romer (1991) with respect to the production of machines. With $R_{j}$ denoting the spending of R\&D for type $j$ machines and $\eta_{j}$ being constant scale factors allowing for the costs of innovations in the two sectors to differ, we have

$$
\dot{N}_{K}=\eta_{K} R_{K} \quad \text { and } \quad \dot{N}_{L}=\eta_{L} R_{L} .
$$


In steady state, $N_{K}$ and $N_{L}$ grow at the same rate. This implies the technologymarket-clearing condition

$$
\eta_{K} \pi_{K}=\eta_{L} \pi_{L}
$$

From (45) we get relative profits as

$$
\frac{\pi_{K}}{\pi_{L}}=\frac{\eta_{L}}{\eta_{K}}
$$

With (31) we solve for the steady-state ratio of $N_{K}$ and $N_{L}$ as

$$
\frac{N_{K}}{N_{L}}=\eta \phi(\underline{z}, \bar{z})
$$

where $\eta \equiv \eta_{K} / \eta_{L}$. Hence, the higher the average capital intensity of the range of final goods produced in the economy, the higher the incentives to innovate in type $K$ machines and the higher the long-run ratio $N_{K} / N_{L}$. Specifically, in the equilibrium of the two-country model with the home country specializing on final products $z \in\left[0, z^{\prime}\right]$, while the foreign country specializes on final products $z \in\left[z^{\prime}, 1\right]$, the long-run ratio $N_{K} / N_{L}$ is given by

$$
\frac{N_{K}}{N_{L}}=\eta \phi\left(0, z^{\prime}\right)<\frac{N_{K}^{*}}{N_{L}^{*}}=\eta \phi\left(z^{\prime}, 1\right) .
$$

The result in 47 is just what we supposed for our analysis of the static equilibrium. 